\title{
АЛМАЗЫ СВИТЫ КЕЙВ (КОЛЬСКИЙ ПОЛУОСТРОВ)
}

Каржавин В.К.

Геологический институт КНЦ РАН, Апатиты, karzhavin@geoksc.apatity.ru

\section{Аннотация}

В статье показаны условия образования и существования обеих полиморфных модификаций углерода в широком интервале температуры и давления в природных условиях. Образование алмаза и углерода может быть реализовано при наличии углеродсодержащих пород (или определённой концентрации углерода) в близповерхностных и поверхностных восстановительных условиях при низкой величине парциального давления кислорода. Выявлены характерные изменения в составе твёрдой фазы в присутствии восстановленного флюида.

Предполагают, что алмазы образовались на глубинах в пределах 400 километров. Затем, в зависимости от геодинамических условий, быстро выносились магмой к поверхности Земли. Однако после образования алмаза в области высоких Р и Т, кристалл будет находиться в сверхсжатом состоянии (в виде плотной структуры вещества). Поэтому чтобы этот кристалл оказался на поверхности Земли он должен, как предполагают многие исследователи, перемещаться с глубин с высокой скоростью [14]. Стремительный подъём к земной поверхности по разломам даже со скоростью 30-50 метров в секунду с глубины 200-300 км составит 3.5-4 часа. В результате такой «транспортировки», сопровождаемой резким сбросом давления, кристалл алмаза разуплотняется (дилатансия) и от него ничего не остается, кристалл просто рассыпается. Это закон физики.

Присутствие алмазов в некимберлитовых породах (метаморфических) предложено рассматривать как возможность их генезиса по иному механизму $[10,13,17]$. В качестве подтверждения этому приводят случаи находок древесины, замещённой кальцитом, а также частично опалом и халцедоном в кимберлитовых трубках взрыва Якутской, Южно-Африканской и СевероРусской провинций. Вместе с тем, иногда внутри кристаллов сибирских алмазов находили даже тонкие веточки растений [16].

Впервые теоретические результаты определения полей устойчивости полиморфных модификаций углерода термодинамическими расчётами линий фазового равновесия углерод - алмаз были осуществлены О.И. Лейпунским [11]. Предсказанный им переход углерода в алмаз может осуществляться при давлении 60 кбар и температуре 2300 К. Впоследствии появилось ряд уточняющих теоретических работ по определению равновесных условий графит - алмаз [18-20] и др. (рис. 1). Даже было рассчитано, что при космическом абсолютном нуле $\left(0 \mathrm{~K}=-273.16^{\circ} \mathrm{C}\right)$ это равновесие составляет около 1500 Мн/м² (15 кбар) [3]. Это означает, что для метеоритной (межзвёздной) гипотезы образования алмазов также требуются высокие давления (в условиях вакуума!). 


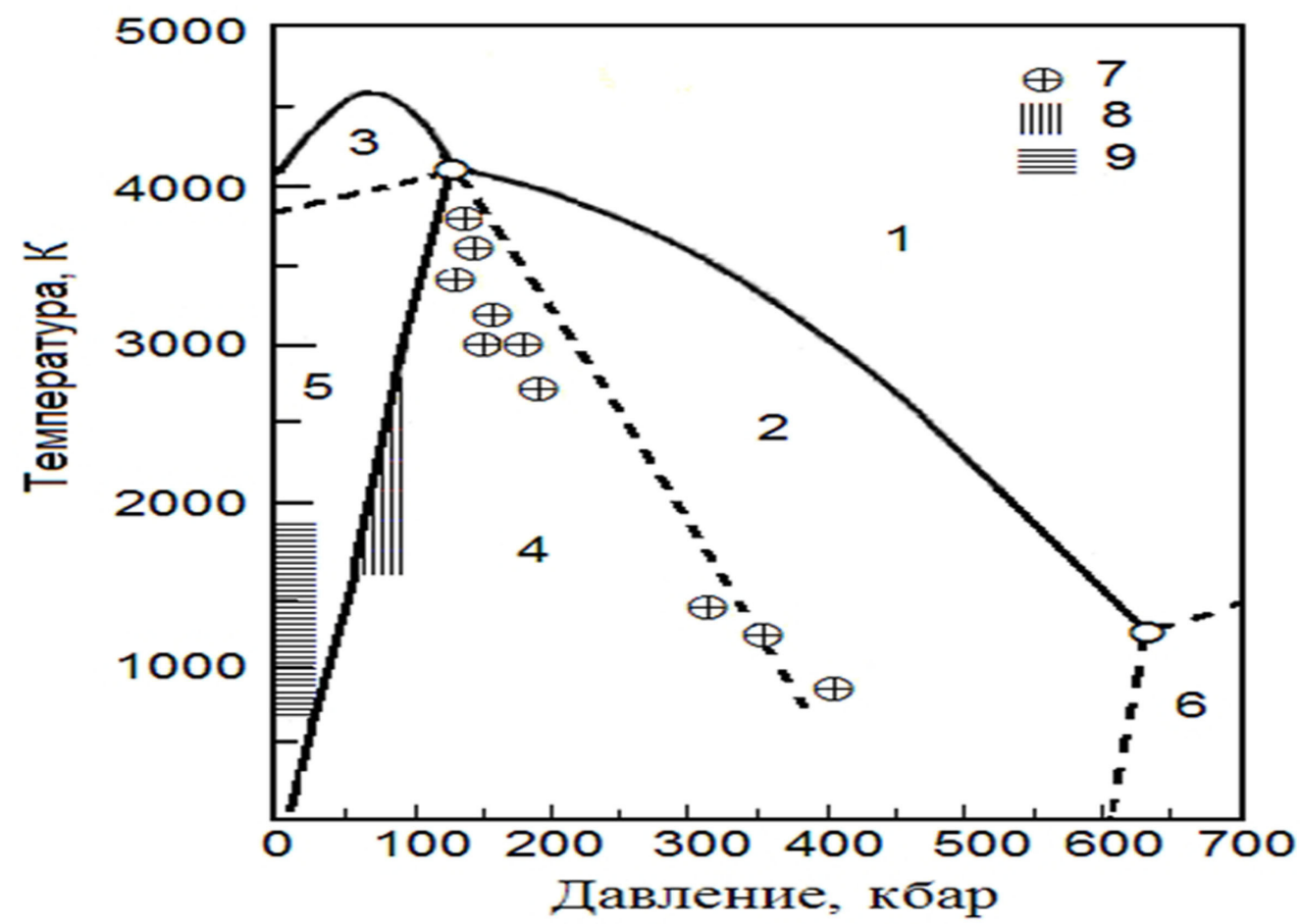

Рис. 1. Области существования углерода в различных состояниях (диаграмма состояния): 1 -жидкость; 2 -стабильный алмаз; 3 -стабильный графит; 4 -стабильный алмаз и метастабильный графит: 5 - стабильный графит и метастабильный алмаз; 6 - гипотетическая область существования иных твёрдых состояний углерода; 7 - кружки, соответствующие условиям опьтов по прямому преврашению графита в алмаз; 8-область образования алмаза с использованием металлов (как катализаторы); 9 - область экспериментов по образованию алмазов при низком давлении [1, 3].

На рисунке (рис. 2) представлено совмещение Р-Т диаграммы $\mathrm{Al}_{2} \mathrm{SiO}_{5} \mathrm{c}$ Р-Т диаграммой фазового равновесия алмаз-углерод. Такое совмещение качественно указывает на некоторые интересные выводы. Из данного рисунка видно, что область существования кианита в системе Ky-Sill-And и области метастабильного алмаза, графита и алмаза с метастабильным графитом фазовой диаграммы алмаз-графит имеют аналогичные термодинамические параметры. Это означает, что в Р-Т области существования кианита в системe Ky-Sill-And и области метастабильного алмаза с графитом показана возможность кристаллизации и совместного существования обеих полиморфных модификаций углерода при температуре ниже $1000^{\circ} \mathrm{C}$. Поэтому возможная совместная кристаллизация алмаза и графита в алюмосиликатной системе свидетельствует об относительно низкотемпературных условиях их образования. Однако при этих термодинамических параметрах велика вероятность последующего превращения метастабильного алмаза в графит (графитизация). Данный процесс является медленным во времени и сопровождается выделением энергии 2.18 кДж/моль. Именно это явление отмечают многие исследователи алмазов различных месторождений, в которых встречаются кристаллы, покрытые так называемыми графитовыми «рубашками». 


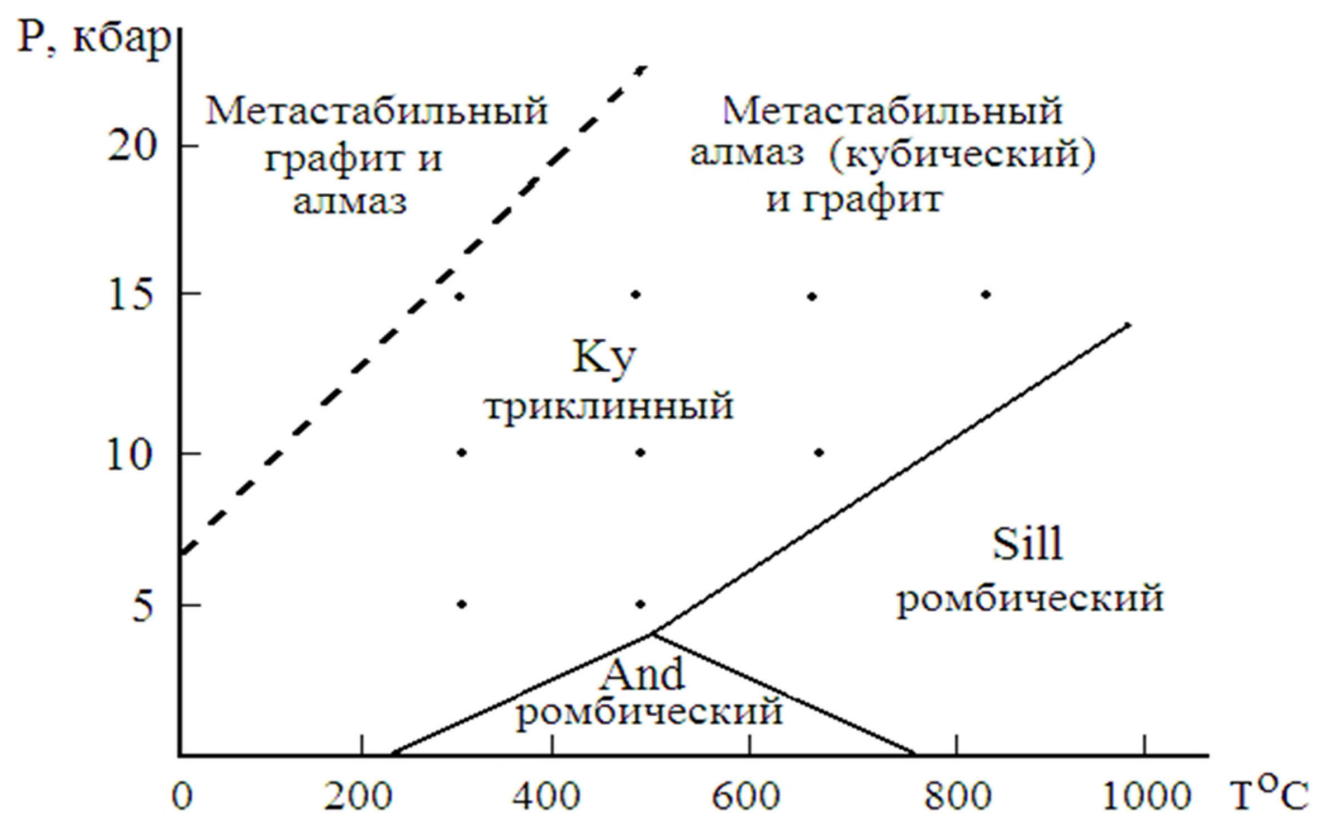

Puc. 2. Совмещённая $\mathrm{P}-\mathrm{T}$ диаграмма $\mathrm{Al}_{2} \mathrm{SiO}_{5}$ с фазовой $\mathrm{P}-\mathrm{T}$ диаграммой состояния углерода.

Предварительно были рассмотрены некоторые реакции возможного образования граната (альмандина) в алюмосиликатной системе, которые соответствуют следующим химическим реакциям (с участием сидерита) [7]:

$$
\begin{aligned}
& 3 \mathrm{FeCO}_{3}+\mathrm{Al}_{2} \mathrm{O}_{3}+3 \mathrm{SiO}_{2}=\mathrm{Fe}_{3} \mathrm{Al}_{2} \mathrm{Si}_{3} \mathrm{O}_{12}+3 \mathrm{C}+3 \mathrm{O}_{2} \\
& 3 \mathrm{FeCO}_{3}+\mathrm{Al}_{2} \mathrm{SiO}_{5}+2 \mathrm{SiO}_{2}=\mathrm{Fe}_{3} \mathrm{Al}_{2} \mathrm{Si}_{3} \mathrm{O}_{12}+3 \mathrm{C}+3 \mathrm{O}_{2}
\end{aligned}
$$

А также граната с кианитом:

$$
\begin{aligned}
& 3 \mathrm{FeCO}_{3}+5 \mathrm{Fe}_{3} \mathrm{Al}_{2} \mathrm{Si}_{3} \mathrm{O}_{12}=3 \mathrm{C}+5 \mathrm{Al}_{2} \mathrm{SiO}_{5}+6 \mathrm{Fe}_{3} \mathrm{O}_{4}+10 \mathrm{SiO}_{2} \\
& 3 \mathrm{FeCO}_{3}+5 \mathrm{Fe}_{3} \mathrm{Al}_{2} \mathrm{Si}_{3} \mathrm{O}_{12}+10 \mathrm{Al}_{2} \mathrm{O}_{3}=3 \mathrm{C}+6 \mathrm{Fe}_{3} \mathrm{O}_{4}+15 \mathrm{Al}_{2} \mathrm{SiO}_{5} \\
& 3 \mathrm{FeCO}_{3}+3 \mathrm{Al}_{2} \mathrm{SiO}_{5}=3 \mathrm{C}+\mathrm{Fe}_{3} \mathrm{Al}_{2} \mathrm{Si}_{3} \mathrm{O}_{12}+2 \mathrm{Al}_{2} \mathrm{O}_{3}+3 \mathrm{O}_{2} \\
& \mathrm{FeCO}_{3}+\mathrm{Al}_{2} \mathrm{SiO}_{5}+2 \mathrm{SiO}_{2}=3 \mathrm{C}+\mathrm{Fe}_{3} \mathrm{Al}_{2} \mathrm{Si}_{3} \mathrm{O}_{12}+3 \mathrm{O}_{2}
\end{aligned}
$$

Этими реакциями показана возможность совместного существования графита (алмаза), граната, кианита, сидерита, оксидов железа и алюминия в природных равновесных условиях (рис. 3,4 ).

Теоретическое физико-химическое моделирование природных процессов осуществляется обычно с помощью метода минимизации свободной энергии Гиббса (программа «Селектор»), совмещенная с базами термоди-

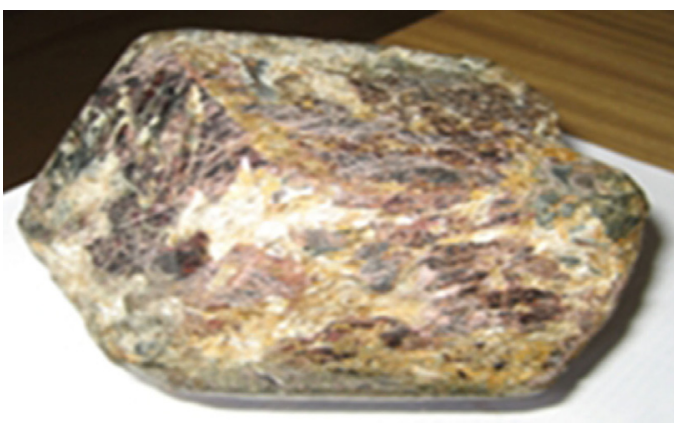

Рис. 3. Образеи граната.

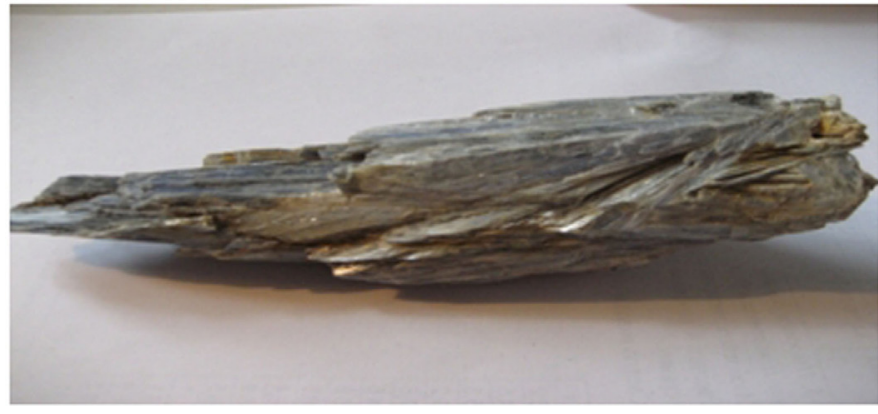

Рис. 4. Образеи кианита. 
намических величин, что позволяет осуществлять расчёт с высокой точностью $[8,9]$. «Селектор» является интегрированной модульной системой, включающей список химических элементов и несколько баз исходных термодинамических данных элементов и химических соединений (минералов), для создания которых автор использовал справочную литературу [21] и банк термодинамических данных ИВТАНТЕРМО [6].

Для проведения исследования была создана мультисистема, основой состава которой являются независимые компоненты (элементы). Для создания векторов исследуемой системы

\section{Al-Fe-Mg-Si-Ti-C-S-H-O}

были использованы результаты химического анализа образца кианита 352/10 (Тяпшманюку) (табл. 1) [12]. В кианит-силлиманитовых сланцах больших Кейв наряду с оксидами углерода и углеводородными газами парафинового ряда методом ДТА был установлен факт одновременного присутствия двух различных модификаций углерода (аморфная и кристаллическая) до 3.42 масс.\% $[2,5]$. Тёмный цвет кианитовых сланцев обязан именно присутствию в них тонкодисперсного углеродистого вещества (графитоида).

Таблица 1. Химический состав и созданные для исследования вектора $b_{\text {i }}$ природного образца.

\begin{tabular}{|c|c|c|c|c|c|}
\hline \multirow{3}{*}{$\begin{array}{l}\text { Хим. } \\
\text { состав }\end{array}$} & \multirow{3}{*}{ Мac. $\%$} & \multicolumn{4}{|c|}{ Вектора } \\
\hline & & $b_{1}$ & $b_{2}$ & $b_{3}$ & $b_{4}$ \\
\hline & & \multicolumn{4}{|c|}{ моль/кг } \\
\hline $\mathrm{SiO}_{2}$ & 61.89 & 10.5050 & 10.3891 & 10.089 & 9.96472 \\
\hline $\mathrm{TiO}_{2}$ & 1.75 & 0.2192 & 0.21562 & 021461 & 0.21197 \\
\hline $\mathrm{Al}_{2} \mathrm{O}_{3}$ & 28.67 & 5.6275 & 5.53291 & 5.50797 & 5.44036 \\
\hline $\mathrm{Fe}_{2} \mathrm{O}_{3}$ & 0.62 & - & - & - & - \\
\hline $\mathrm{FeO}$ & 1.25 & 0.2518 & 0.24994 & 0.24642 & 0.24344 \\
\hline $\mathrm{MgO}$ & 0.49 & 0.1217 & 0.01204 & 0.1191 & 0.11761 \\
\hline $\mathrm{CaO}$ & 0.26 & 0.0464 & 0.04530 & 0.04542 & 0.04485 \\
\hline $\mathrm{Na}_{2} \mathrm{O}$ & 1.31 & 0.4229 & 0.41805 & 0.4140 & 0.40894 \\
\hline $\mathrm{K}_{2} \mathrm{O}$ & 1.16 & 0.2464 & 0.24168 & 0.24122 & 0.23827 \\
\hline$\sum \mathrm{H}_{2} \mathrm{O}$ & 0.06 & 2.4658 & 2.44865 & 2.41384 & 2.38422 \\
\hline $\mathrm{S}_{\text {общ. }}$ & 0.07 & 0.0218 & 0.0193 & 0.01542 & 0.02112 \\
\hline $\mathrm{CO}_{2}$ & 0.1 & 0.0227 & 0.9032 & 1.78366 & 2.76262 \\
\hline $\mathrm{Ni}$ & 0.01 & 0.0017 & 0.0017 & 0.00167 & 0.00165 \\
\hline $\mathrm{Cu}$ & 0.01 & 0.0025 & 0.0016 & 0.00154 & 0.00152 \\
\hline $\mathrm{P}_{2} \mathrm{O}_{5}$ & 0.13 & 0.0184 & 0.0180 & 0.01794 & 0.00830 \\
\hline П.п.п. & 2.16 & - & - & - & - \\
\hline$\sum \mathrm{O}$ & & 30.6593 & 30.3882 & 30.3313 & 30.3174 \\
\hline
\end{tabular}


Физико-химическое моделирование проводилось для $\mathrm{T}=300,500,700$ и $900^{\circ} \mathrm{C}$ и давления $\mathrm{P}=1,5$ и 10 кбар. Для теоретических расчётов основными компонентами алюмосиликатной системы в составе твердой фазы приняты кианит, силлиманит, андалузит, а также гранат (альмандин, пироп) с углеродом и ряд газообразных соединений системы С-H-O [4].

Предпринятая для проведения исследования область Р-Т параметров (рис. 2) представляет определённые экспериментальные условия синтеза (образования) алмазов при низком давлении, отличных от высокобарических [15]. Результатами экспериментов в данной области являются, как правило, стабильный графит и метастабильное существование алмаза (рис. 1). Используемое содержание углерода в мультисистемах (векторах) находилось в пределах от 0.9032 до 2.7626 моль/кг (3.42 мас. \%). Это позволит оценить роль переменной концентрации углерода (и кислорода) в исследуемых системах. Для проведения исследования были сформированы мультисистемы $b_{1}-b_{4}$ (табл. 1 ).

Анализ результатов численного моделирования позволил установить некоторые интересные отличия, которые можно проследить на примере твёрдой фазы и состава флюида. В качестве примера в таблице приведены результаты расчёта, проведённые в области широкого интервала давления и температуры (табл. 2). Действительно, образование алмаза в данной системе возможно, причем совместно с углеродом в восстановительной обстановке. Причём, по результатам расчётов следует, что содержание углерода в исследуемой системе превышает количество образующего алмаза в два и более раза.

В результате проведённого физико-химического моделирования векторов $b_{2}-b_{4}$ было установлено, что основными компонентами в твёрдой фазе исследуемых систем являются кварц, альмандин и пироп, а кианит, силлиманит, альмандин в соответствии с их полями на Р-Т диаграмме (рис. 2). Кроме них в составе твёрдой фазы отмечается незначительное содержание ставролита, микроклина, а также титансодержащих минералов: ильменита, сфена, рутила. Установлены практически стабильные содержания кианита, альбита, анортита, ставролита, а также титансодержащих минералов. Вместе с тем прослеживается снижение содержаний биотита, мусковита и хлорита. Из сульфидных минералов более стабильными оказались $\mathrm{NiS}_{2}$ (в области низких температур) и $\mathrm{FeS}$ (в области высоких). Следует отметить характерное влияние содержания углерода на интересные условия образования апатита: при незначительном содержании углерода (вектор $b_{4}$ ) присутствует только гидроксилапатит, а с повышением содержания углерода в системе вместо него появляется карбонатапатит (табл. 2).

Из результатов расчёта следует, что флюидная фаза в исследуемой системе восстановительная в основном водоуглекислая с высокой концентрацией воды и содержит незначительные концентрации $\mathrm{CO}_{2}, \mathrm{CH}_{4}, \mathrm{H}_{2} \mathrm{~S}$ и др.

В качестве примера на рис. 5 представлены в графической форме результаты физико-химического моделирования изменения содержания углерода, 


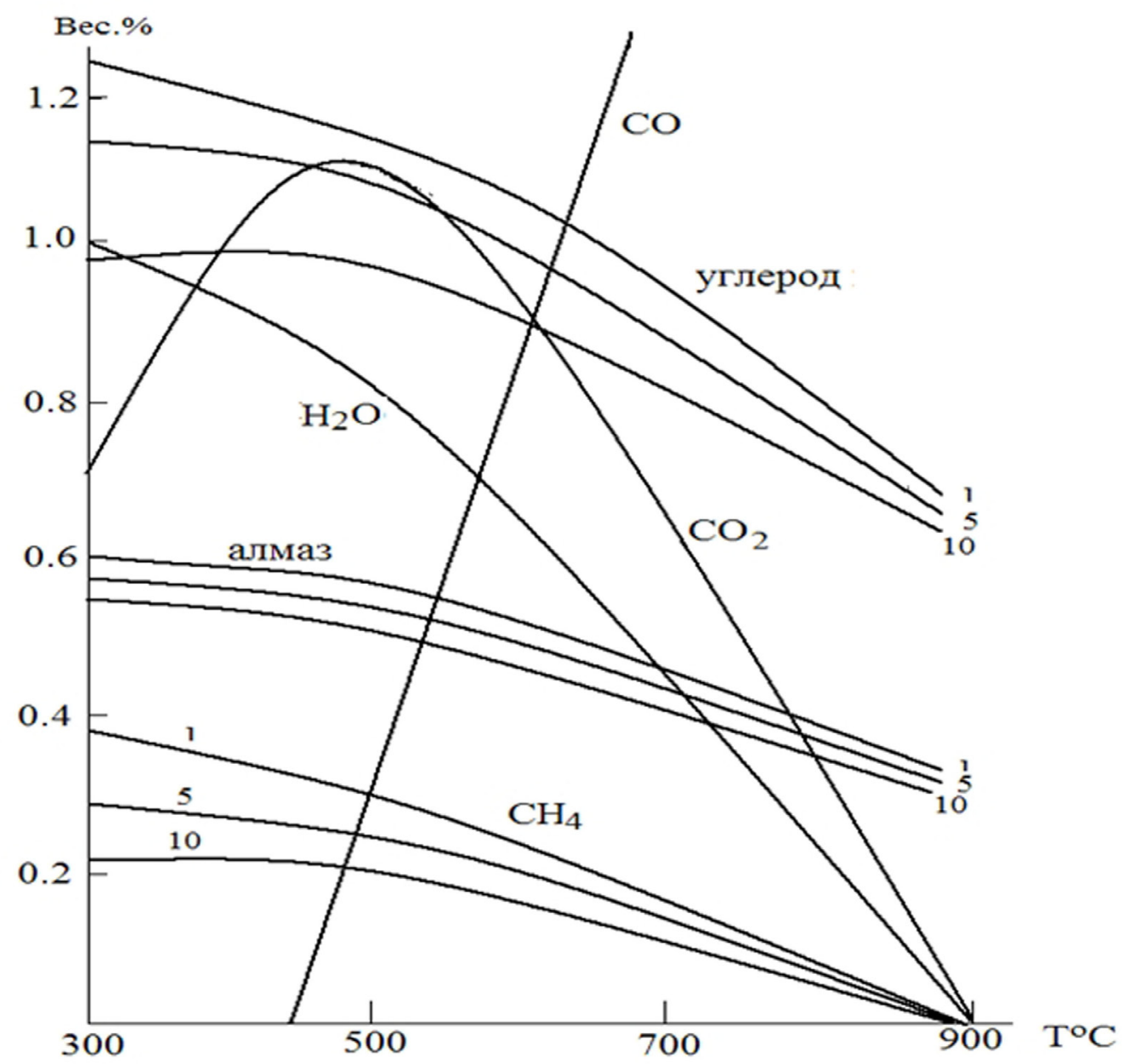

Рис. 5. Распределение концееттраций углерода, алмаза и летучих компонентов флюида в зависимости от концентрации кислорода, температуры и разньх величин давления.

алмаза и летучих компонентов флюида в зависимости от концентрации кислорода, температуры и разных величин давления в исследуемой системе.

\section{Выводы}

В результате проведённого исследования установлены низкотемпературные условия совместной (ассоциация) кристаллизации графита и алмаза при повышенных величинах общего давления (область метастабильного существования алмаза) и низком содержании кислорода в алюмосиликатной системе. В связи с изложенным материалом предлагается считать возможным наличие и других путей синтеза алмаза в природных условиях, отличных от высокобарического. В зависимости от Р-Т параметров исследуемой системы и концентрации углерода нам удалось установить некоторые характерные особенности и прийти к следующему выводу: из полученного расчётного материала следует, что основными компонентами в твёрдой фазе исследуемых систем являются кианит и гранат. На основании ранее проведённых нами исследований можно считать кристаллы граната (альмандин) наибольшим концентратором наноразмерных алмазов в сложной алюмосиликатной системе Кейв. 
Таблица 2. Результаты расчёта компонентов твёрдой фазы и флюида (вектор $b_{4}$ ) при разных величинах давления и температуры.

\begin{tabular}{|c|c|c|c|c|c|c|c|c|c|}
\hline \multirow{3}{*}{ Состав } & 300 & 500 & 300 & 500 & 700 & 300 & 500 & 700 & 900 \\
\hline & \multicolumn{2}{|c|}{5 кбар } & \multicolumn{3}{|c|}{10 кбар } & \multicolumn{4}{|c|}{15 кбар } \\
\hline & \multicolumn{9}{|c|}{ Содержание, мас.\% } \\
\hline Углерод & 2.20 & 2.18 & 2.06 & 2.06 & 2.07 & 1.92 & 1.95 & 1.98 & 2.00 \\
\hline Алмаз & 1.10 & 1.13 & 1.24 & 1.23 & 1.23 & 1.39 & 1.34 & 1.31 & 1.29 \\
\hline $\mathrm{CaCO}_{3}$ & - & - & 0.08 & - & - & сл. & 0.001 & сл. & - \\
\hline $\mathrm{MgCO}_{3}$ & - & - & 0.03 & - & - & сл. & 0.14 & 0.21 & - \\
\hline $\mathrm{CaMg}\left(\mathrm{CO}_{3}\right)_{2}$ & - & - & 0.08 & - & - & сл. & 0.002 & сл. & - \\
\hline Кианит & 25.58 & 26.27 & 25.81 & 25.62 & 35.61 & 34.12 & 34.22 & 38.62 & 38.68 \\
\hline Альбит & 10.74 & 10.89 & 10.73 & 10.75 & 10.76 & 10.73 & 10.73 & 10.73 & 10.75 \\
\hline Анортит & 0.43 & 0.43 & 0.08 & 0.43 & 0.43 & 0.43 & 0.42 & 0.43 & 0.42 \\
\hline Микроклин & - & - & - & - & - & - & - & 5.66 & 5.44 \\
\hline Кварц & 35.58 & 36.06 & 35.64 & 36.62 & 34.98 & 35.02 & 35.04 & 33.75 & 33.79 \\
\hline Магнетит & - & - & - & - & - & 0.95 & 0.17 & - & - \\
\hline Аннит & - & - & - & - & 0.40 & - & - & 0.22 & 0.21 \\
\hline Флогопит & - & - & - & - & 1.64 & - & - & 1.29 & 1.64 \\
\hline Мусковит & 9.51 & 9.64 & 9.50 & 9.52 & 7.64 & 9.50 & 9.50 & сл. & - \\
\hline Fe -ставролит & 9.95 & 9.70 & 9.93 & 9.94 & - & - & - & - & - \\
\hline Mg -ставролит & сл. & сл. & сл. & сл. & - & - & - & - & - \\
\hline Хлорит & 1.46 & 1.48 & 1.36 & 1.46 & - & 1.46 & 1.25 & - & - \\
\hline Рутил & 1.70 & 1.72 & 1.69 & 1.70 & 0.09 & 0.81 & сл. & сл. & сл. \\
\hline Ильменит & - & - & - & - & 3.06 & 1.68 & 3.22 & 3.22 & 3.22 \\
\hline $\mathrm{NiS}$ & 0.003 & 0.004 & 0.004 & 0.006 & 0.004 & 0.004 & 0.006 & 0.005 & 0.004 \\
\hline $\mathrm{NiS}_{2}$ & 0.017 & 0.001 & 0.014 & 0.009 & 0.001 & 0.003 & 0.007 & 0.004 & 0.001 \\
\hline $\mathrm{Ni}_{3} \mathrm{~S}_{2}$ & сл. & сл. & сл. & 0.002 & 0.009 & 0.008 & 0.003 & 0.006 & 0.009 \\
\hline FeS & - & 0.16 & - & сл. & 0.17 & - & сл. & 0.16 & 0.17 \\
\hline $\mathrm{FeS}_{2}$ & 0.10 & - & 0.11 & 0.11 & - & 0.11 & 0.11 & - & - \\
\hline $\mathrm{Cu}_{2} \mathrm{~S}$ & 0.012 & 0.012 & 0.012 & 0.012 & 0.012 & 0.012 & 0.012 & 0.012 & 0.012 \\
\hline $\mathrm{CO}_{3}-$ Апатит & 0.306 & 0.310 & 0.307 & 0.311 & 0.312 & 0.303 & 0.305 & .306 & - \\
\hline ОН -Апатит & - & - & - & - & - & - & - & - & 0.297 \\
\hline $\mathrm{H}_{2} \mathrm{O}$ & 1.22 & - & 1.33 & 1.22 & 1.60 & 1.53 & 1.56 & 2.09 & 2 \\
\hline & & & Парциа & ьное дав. & ение $\left(\mathrm{P}_{\mathrm{i}}\right.$ & бар & & & \\
\hline $\mathrm{H}_{2}$ & $1.0 \mathrm{e}-1$ & $4.9 \mathrm{e}-0$ & $4.2 \mathrm{e}-3$ & $6.7 \mathrm{e}-1$ & $1.0 \mathrm{e}+1$ & $3.8 \mathrm{e}-4$ & $2.4 \mathrm{e}-2$ & $5.7 \mathrm{e}-1$ & $4.3 \mathrm{e}-0$ \\
\hline $\mathrm{H}_{2} \mathrm{O}$ & $1.1 \mathrm{e}-12$ & $4.7 \mathrm{e}+3$ & $1.7 \mathrm{e}+3$ & $7.3 e+3$ & $7.2 \mathrm{e}+3$ & $33.8 \mathrm{e}-9$ & $6.9 \mathrm{e}+2$ & $1.4 \mathrm{e}+3$ & $2.1 \mathrm{e}+3$ \\
\hline $\mathrm{H}_{2} \mathrm{~S}$ & $2.0 \mathrm{e}-0$ & $8.5 \mathrm{e}-0$ & $2.9 \mathrm{e}-2$ & $4.3 \mathrm{e}-0$ & $1.8 \mathrm{e}+1$ & $2.6 \mathrm{e}-4$ & $8.3 \mathrm{e}-2$ & $1.8 \mathrm{e}-0$ & $7.7 \mathrm{e}-0$ \\
\hline $\mathrm{O}_{2}$ & $4.3 e-37$ & $5.3 \mathrm{e}-25$ & $3.5 \mathrm{e}-35$ & $7.0 \mathrm{e}-24$ & $2.3 \mathrm{e}-18$ & $3.4 \mathrm{e}-35$ & $8.8 \mathrm{e}-24$ & $7.0 \mathrm{e}-18$ & $5.1 \mathrm{e}-14$ \\
\hline $\mathrm{SO}_{2}$ & $3.1 \mathrm{e}-8$ & $1.3 \mathrm{e}-7$ & $7.8 \mathrm{e}-9$ & $6.3 e-6$ & $9.3 e-5$ & $7.4 \mathrm{e}-12$ & $4.1 \mathrm{e}-6$ & $4.8 \mathrm{e}-4$ & $7.0 \mathrm{e}-3$ \\
\hline $\mathrm{CO}$ & $8.9 e-3$ & $3.2 \mathrm{e}-1$ & $2.7 e-3$ & $5.1 \mathrm{e}-1$ & $1.2 \mathrm{e}+1$ & $9.7 e-5$ & $2.7 \mathrm{e}-1$ & $1.1 \mathrm{e}+1$ & $1.3 \mathrm{e}+2$ \\
\hline $\mathrm{SO}_{2}$ & $3.1 \mathrm{e}-8$ & $1.3 \mathrm{e}-7$ & $7.8 \mathrm{e}-9$ & $6.3 e-6$ & $9.3 e-5$ & $7.4 \mathrm{e}-12$ & $4.1 \mathrm{e}-6$ & $4.8 \mathrm{e}-4$ & $7.0 \mathrm{e}-3$ \\
\hline $\mathrm{CO}$ & $8.9 e-3$ & $3.2 \mathrm{e}-1$ & $2.7 \mathrm{e}-3$ & $5.1 \mathrm{e}-1$ & $1.2 \mathrm{e}+1$ & $9.7 e-5$ & $2.7 \mathrm{e}-1$ & $1.1 \mathrm{e}+1$ & $1.3 \mathrm{e}+2$ \\
\hline $\mathrm{CO}_{2}$ & $5.0 \mathrm{e}+3$ & $2.4 \mathrm{e}+2$ & $3.1 \mathrm{e}+3$ & $2.7 e+3$ & $2.8 \mathrm{e}+3$ & $2.3 \mathrm{e}+1$ & $2.6 \mathrm{e}+3$ & $6.6 \mathrm{e}+3$ & $1.3 \mathrm{e}+4$ \\
\hline $\mathrm{CH}_{4}$ & $4.6 \mathrm{e}-0$ & $7.1 \mathrm{e}+1$ & $1.2 \mathrm{e}-2$ & $1.7 \mathrm{e}-0$ & $1.8 \mathrm{e}+1$ & $3.1 \mathrm{e}-4$ & $2.7 \mathrm{e}-3$ & $6.2 \mathrm{e}-2$ & $4.4 \mathrm{e}-1$ \\
\hline $\mathrm{C}_{2} \mathrm{H}_{6}$ & $8.7 e-5$ & $1.7 \mathrm{e}-2$ & $1.6 \mathrm{e}-8$ & $7.8 \mathrm{e}-5$ & $55.6 \mathrm{e}-3$ & $2.3 \mathrm{e}-11$ & $5.9 \mathrm{e}-9$ & $1.4 \mathrm{e}-6$ & $4.1 \mathrm{e}-5$ \\
\hline $\mathrm{S}_{2}$ & $6.3 \mathrm{e}-10$ & $1.9 \mathrm{e}-7$ & $2.1 \mathrm{e}-10$ & $6.1 \mathrm{e}-6$ & $2.0 \mathrm{e}-4$ & $6.8 \mathrm{e}-12$ & $4.5 \mathrm{e}-6$ & $1.3 \mathrm{e}-3$ & - \\
\hline $\mathrm{V}_{\mathrm{ra3},} \mathrm{cM}^{3}$ & 0.72 & 16.6 & 70.2 & 1.62 & 2.15 & 92.6 & 93.2 & 105.7 & 0.98 \\
\hline Основной газ & $\mathrm{CO}_{2}$ & $\mathrm{H}_{2} \mathrm{O}$ & $\mathrm{CO}_{2}$ & $\mathrm{H}_{2} \mathrm{O}$ & $\mathrm{H}_{2} \mathrm{O}$ & $\mathrm{CO}_{2}$ & $\mathrm{CO}_{2}$ & $\mathrm{CO}_{2}$ & $\mathrm{CO}_{2}$ \\
\hline
\end{tabular}




\section{Список литературы}

1. Безруков Г.Н., Бутузов В.П., Горохов С.С. Генетическое значение морфологических особенностей синтетических и природных алмазов // Типоморфизм минералов и его практическое значение М.: Недра. 1972. С. 83-86. 2. Бельков И.В. Кианитовые сланцы свиты Кейв. М.-Л.: Изд-во АН СССР. $1963.321 \mathrm{c}$

3. Бутузов В.П. Методы получения искусственных алмазов / Исследование природного и технического минералообразования. М.: Наука. 1966.

4. Зубков В.С. К вопросу о составе и формах нахождения флюида системы C-H-N-O-S в РТ- условиях верхней мантии // Геохимия. 2001. № 2. С. 131-145. 5. Гинсбург И.В., Горшков А.И. О графите кианитовых сланцев Кейв (Кольский полуостров) / Тр. Минерал. музея им. А.Е. Ферсмана. М.: Изд-во АН СССР. 1961. Вып. 12. С. 171-176.

6. ИВТАНТЕРМО, 2006. http://www.chem.msu.su/cgi-bin/tkv2.pl.

7. Каржавин B.К. Условия образования алмазов. LAP LAMBERT, Academic Publishing RU. 2018. P. 111.

8. Карпов И.К., Киселёв А.И., Летников Ф.А. Моделирование природного минералообразования на ЭВМ. М.: Недра. 1976. 256 с.

9. Карпов И.К. Физико-химическое моделирование на ЭВМ в геохимии. Новосибирск: Наука. 1981. 248 с.

10. Лаврова Л.Д., Печников В.А., Плешаков А.М. и др. Новый генетический тип алмазных месторождений. М.: Научный мир. 1999. 228 с.

11. Лейпунский О.И. Об искусственных алмазах // Успехи химии. 1939. T. VIII. Вып. 10. С. 1519-1534.

12. Нерадовский Ю.Н., Войтеховский Ю.Л. Атлас структур и текстур кристаллических сланцев Больших Кейв. Апатиты: Изд-во К\&М. 2013. 116 с.

13. Сидоренко А.В., Розен О.М., Теняков В.А., Сидоренко Св.А. Углеродсодержащие метаморфические комплексы докембрия как потенциальный источник алмаза // ДАН СССР. 1976. Т. 230. № 6. С. 1433-1436.

14. Соболев В.С, Шацкий Н.В. Некоторые аспекты генезиса алмазов в метаморфических породах // ДАН РАН. 1993. Т. 331. № 2. С. 217-219.

15. Харькив А.Д. Зинчук Н.Н., Зуев В.М. История алмаза. М.: Недра.1997. 601 с. 16. Шестаков О.В. Образование, свойства и добыча алмазов (http://bestreferat.ru/referat-178261).

17. Шумилова Т.Г. Минералогия самородного углерода. Екатеринбург: Уро PAH. 2003. 315 c.

18. Berman R.G., Simon F. On the graphite-diamond equilibrium // Zeitschrift fur Electrochemie. 1955. V. 59. N. 5. P. 333-338.

19. Bundy F.P. The P,T phase and reaction diagram for elemental carbon, 1979 // J. Geophys. Res. 1980. V. 85. P. 6930-6939.

20. Kennedy C.S., Kennedy G.C. The equilibrium boundary between graphite and diamond // J.Geophys. Res. 1976. V. 8. N 14. P. 2467-2470.

21. Yokokawa H. Tables thermodynamic properties of inorganic components. Kagaku gidziutsu kenkiudze kokaku (Jour. Nat. Chem. Lab. Ind. - Spec. Iss.). V. 83. 1988. $121 \mathrm{p}$. 